\title{
Comparative Study between Dexmedetomidine Versus Dexamethasone as Adjuvants to Levobupivacaine for Cervical Plexus Block in Patients Undergoing Thyroid Operation. Prospective-Randomized Clinical Trial
}

Ahmed Hamody Hassan ${ }^{1}$, Islam A. Amer ${ }^{2}$, Ayman Mohamed Abdelkareem ${ }^{1}$

Departments of ${ }^{1}$ Anesthesia and Intensive Care and Pain Management and ${ }^{2}$ Maxillofacial, Head and Neck Surgery

Unit, General Surgery, Faculty of Medicine, Sohag University, Egypt

*Corresponding author: Ayman Mohamed Abdelkareem, Mobile: (+20) 01021330778,

E-Mail: aymann8100@gmail.com

\begin{abstract}
Background: Thyroidectomy is the most common endocrine surgical procedure, and many challenges are encountered during the preoperative, intraoperative, and postoperative periods. After thyroidectomy, bilateral superficial cervical block is the most successful option reducing postoperative pain, analgesic needs and postoperative complications such as vomiting.

Objective: Our study aimed to evaluate the analgesic effect, onset time of sensory block, duration time, postoperative visual analogue score (VAS) and complications of adding dexmedetomidine versus dexamethasone to levobupivacaine for cervical plexus block.

Patients and Methods: A prospective-randomized clinical trial study that was conducted at Sohag University between April 2018 and March 2020. The study included fifty patients with (ASA) Class I or II, aged 30 to 60 years were scheduled for euthyroid surgeries (including thyroid adenoma, Hashimoto's goiter, and nodosity thyroiditis)

Results: The addition of dexmedetomidine to levobupivacaine (group D) shortened the sensory block onset time compared to dexamethasone added to the levobupivacaine group (group $S)(\mathrm{p}<0.05)$. The duration of analgesia of cervical plexus block in group (D) was significantly longer than that in group (S) (232.34 versus 303.55 min; $p<$ $0.05)$. HR level in group (D) was significantly lower than that in group $(\mathrm{S})(\mathrm{p}<0.05)$.

Conclusion: The addition of $1 \mu \mathrm{g} \mathrm{kg}-1$ dexmedetomidine to levobupivacaine for cervical plexus block (BSCPB) shortened the sensory block onset time and extended the duration of analgesia and increased the quality of analgesia more superior than the addition of dexamethasone.
\end{abstract}

Keywords: Cervical plexus block, Levobupivacaine, Dexamethasone; Dexmedetomidine.

\section{INTRODUCTION}

Cervical plexus block is one regional anaesthetic technique, which often used in neck surgery, especially in thyroid surgery (thyroid adenoma, Hashimoto's goiter, and nodular thyroiditis), but if it is used alone its problem that patients awake and arouse. Most surgeons prefer cervical plexus block to general anaesthesia ${ }^{(\mathbf{1})}$. Patients who undergo this form of anaesthesia will experience stress, anxiety, or pain when they are kept awake due to the minor failure of the cervical plexus block, although not all patients will. Adjuvant medications such as midazolam, opioid, remifentanil, and clonidine were used to improve surgical outcomes and make it easier to patients. However, side effects such as oversedation, respiratory depression, hypoxemia, and hypotension can occur due to using these medications. Some researchers have been testing new adjuvant medications with various dosages in recent years to find those that are better for patients ${ }^{(2)}$.

Dexmedetomidine is a highly selective agonist for the $\alpha 2$ adrenergic receptors. Its main site of action is the locus coeruleus in the brainstem. When used as a sedative for patients, it has served as a central antisympathetic, and it may maintain physiological sleep better than any other sedative while also producing analgesic1 and anxiolytic 2 impacts. It does, however, cause some respiratory depression. Because of its pharmacological properties, it is now widely used in intensive care units as sedation and anaesthesia, especially in regional anaesthesia. We currently use dexmedetomidine for regional anaesthesia, as Esmaoglu et al. ${ }^{(3)}$ reported that adding $1 \mathrm{~g} \mathrm{~kg} 1$ dexmedetomidine to lidocaine for IVRA improves the quality of anaesthesia and postoperative analgesia. Dexmedetomidine was found to be safe when used in conjunction with a local anaesthetic for plexus brachialis block in a study by Kaygusuz et al. (4) it may extend the time of anaesthesia and analgesia. Also, Plunkett et al. (5) showed that an awake thyroidectomy with dexmedetomidine (1 g kg1) intravenous infusion and local anaesthesia administered by the surgeon was healthy and without respiratory depression in a case study.

Dexamethasone is a steroid that may relieve pain and therefore the inflammatory response to tissue damage following surgery (heat, pain, redness, and swelling). Dexamethasone may be administered with the local anaesthetic around the nerve (perineural) or into a vein (intravenous) to extend the pain relief from peripheral nerve block ${ }^{(4)}$.

Our study aimed to evaluate the analgesic effect, onset time of sensory block, duration time, 
postoperative visual analogue score (VAS) and complications of adding dexmedetomidine versus dexamethasone to levobupivacaine for cervical plexus block.

\section{PATIENTS AND METHODS}

Fifty patients with (ASA) Class I or II, aged 30 to 60 years, which scheduled for euthyroid surgeries (including thyroid adenoma, Hashimoto's goiter, and nodosity thyroiditis) were enrolled in a prospective-randomized clinical trial study. The study was conducted at Sohag University between April 2018 and March 2020. Patients were randomly allocated to one of two groups: dexmedetomidine $(\mathrm{n}=$ 25 , group $D)$ or dexamethasone $(n=25$, group $S)$ for bilateral superficial cervical plexus block (BSCPB) under sonographic guidance.

Exclusion criteria: Patients on adrenoreceptor agonist or antagonist treatment, as well as those with a history of cardiac, respiratory, hepatic, or renal failure, and those who refused local anaesthesia or had an aversion to local anaesthesia were excluded.

An intravenous line was placed, and ringer lactate $10 \mathrm{~mL} / \mathrm{kg}$ intravenously (IV) was administered after the patient was examined and all investigations were completed. The patient was given oxygen supplementation at a rate of $2 \mathrm{~L} / \mathrm{min}$ via a nasal cannula in the operating room. Under sonographic direction, both groups received a bilateral superficial cervical plexus block. All patients were monitored by an electrocardiogram, pulse oximetry, and noninvasive blood pressure monitoring (BSCPB).

Patients were split into two groups: group $\mathrm{S}$ received $30 \mathrm{~mL}$ of levobupivacaine 0.375 percent with $8 \mathrm{~mL}$ dexamethasone added to the solution. Group D received $30 \mathrm{~mL}$ of levobupivacaine 0.375 percent with $1 \mathrm{~mL}(1 \mathrm{~g} \mathrm{~kg} 1)$ of dexmedetomidine added to the solution. All of the cervical plexus blocks were done by the same anesthesiologist. Both groups received a cervical plexus block, which included both deep and superficial plexus blocks. short-bevel needle was used to inject $10 \mathrm{ml}$ of local anaesthetic solution into the cervical transverse process at $\mathrm{C} 4,2 \times 3 \mathrm{~cm}$ deep from the skin and $1 \mathrm{~cm}$ posterior to the sternocleidomastoid's posterior border. Subcutaneous injection of the remaining $20 \mathrm{~mL}(10 \mathrm{~mL}$ for each side) of the solution along the posterior border of the sternocleidomastoid's middle point completed the superficial block on both sides. Aspiration was used to ensure that there was no blood in the needle hub before injection. Both groups received general anaesthesia after finishing the plexus block. Propofol $2-2.5 \mathrm{mg} / \mathrm{kg}$ IV was used as an induction agent. Atracurium $0.5 \mathrm{mg} / \mathrm{kg}$ IV and lidocaine $2 \mathrm{mg} / \mathrm{kg}$ intratracheally were used to assist with tracheal intubation. Isoflurane and 60 percent oxygen combined with compressed air were used to maintain general anaesthesia. If changes in systolic blood pressure and heart rate exceeded $20 \%$ of basal values, fentanyl $1 \mathrm{mcg} / \mathrm{kg}$ IV was given as an opioid rescue.

Observation: The primary outcome was the assessment of postoperative visual analogue scores (VAS) for both groups at 2, 6, 8, 10 and 12 hours after surgery, as well as the assessment of sensory onset period and duration of time.

Secondary outcomes included monitoring of heart rate (HR) and mean arterial pressure (MAP) at 30, 40, 50, $60,70,80,90,100,110$, and 120 minutes after the start of the operation. Analgesic data such as intraoperative fentanyl use, time to first Diclofenac $\mathrm{Na}$ dose request, and the total amount required postoperative complications, and demographic data (age, sex, weight, and duration of operation) were recorded.

\section{Ethical approval and written informed consent}

An approval of the study was obtained from Sohag University Academic and Ethical Committee. Every patient signed an informed written consent for acceptance of the operation.

\section{Statistical analysis}

The collected data were coded, processed and analyzed using the SPSS (Statistical Package for Social Sciences) version 22 for Windows ${ }^{\circledR}$ (IBM SPSS Inc, Chicago, IL, USA). Data were tested for normal distribution using the Shapiro Walk test. Qualitative data were represented as frequencies and relative percentages. Chi square test $(\chi 2)$ was used to calculate difference between two or more groups of qualitative variables. Quantitative data were expressed as mean \pm SD (Standard deviation). Independent samples t-test was used to compare between two independent groups of normally distributed variables (parametric data). $\mathrm{P}$ value $\leq 0.05$ was considered significant.

\section{RESULTS}

Table (1): Comparing the demographic data between two study group

\begin{tabular}{|l|c|c|c|}
\hline & Group D (25) & Group S (25) & $\begin{array}{c}\text { P- } \\
\text { value }\end{array}$ \\
\hline Age in years & $23.32 \pm 4.21$ & $24.23 \pm 3.21$ & 0.543 \\
\hline $\begin{array}{l}\text { Sex Female } \\
\& \text { Male }\end{array}$ & $4 \& 16$ & $5 \& 15$ & 0.321 \\
\hline $\begin{array}{l}\text { Weight in } \\
\text { kilogram }\end{array}$ & $45.23 \pm 4.23$ & $46.21 \pm 4.32$ & 0.643 \\
\hline $\begin{array}{l}\text { Duration of } \\
\text { surgery(min) }\end{array}$ & $110.21 \pm 12.34$ & $115.43 \pm 22.43$ & 0.521 \\
\hline $\begin{array}{l}\text { ASA } \\
1\end{array}$ & 15 & 16 & 0.97 \\
11 & 10 & 9 & 0.85 \\
\hline
\end{tabular}


Values are presented as mean \pm standard error or number of patients. There were no statistically significant differences between the two study groups as regards age, sex, weight, ASA and duration of operation (Table 1).

Table (2): Comparison between the two groups regarding sensory onset and duration of cervical plexus block

\begin{tabular}{|l|c|c|c|}
\hline & $\begin{array}{c}\text { Group (D) } \\
(\mathbf{n = 2 5})\end{array}$ & $\begin{array}{c}\text { Group } \\
(\mathbf{S})(\mathbf{n}=25)\end{array}$ & $\begin{array}{c}\text { P- } \\
\text { value }\end{array}$ \\
\hline $\begin{array}{l}\text { Time of } \\
\text { onset of } \\
\text { sensory } \\
\text { block (min) }\end{array}$ & $3.64 \pm 32.4$ & $7.62 \pm 45.6$ & 0.007 \\
\hline $\begin{array}{l}\text { Duration } \\
\text { time of } \\
\text { sensory } \\
\text { block (min) }\end{array}$ & $303.55 \pm 26.21$ & $232.34 \pm 54.11$ & 0.004 \\
\hline
\end{tabular}

Data are presented as mean \pm standard error. There was a statistically significant difference between the two groups ( $p$-value $<0.05$. Sensory block onset time in group (D) was shorter $(3.64 \pm 32.4 \mathrm{~min})$ than in group (S) $(7.62 \pm 45.6 \mathrm{~min})$, the difference was statistically significant (p-value was 0.007 ). Sensory block duration time in group (D) $(303.55 \pm 26.21 \mathrm{~min})$ was longer than in group (S) $(232.34 \pm 54.11 \mathrm{~min})$. The difference was statistically significant ( $\mathrm{p}$-value was 0.004 ) (Table 2).

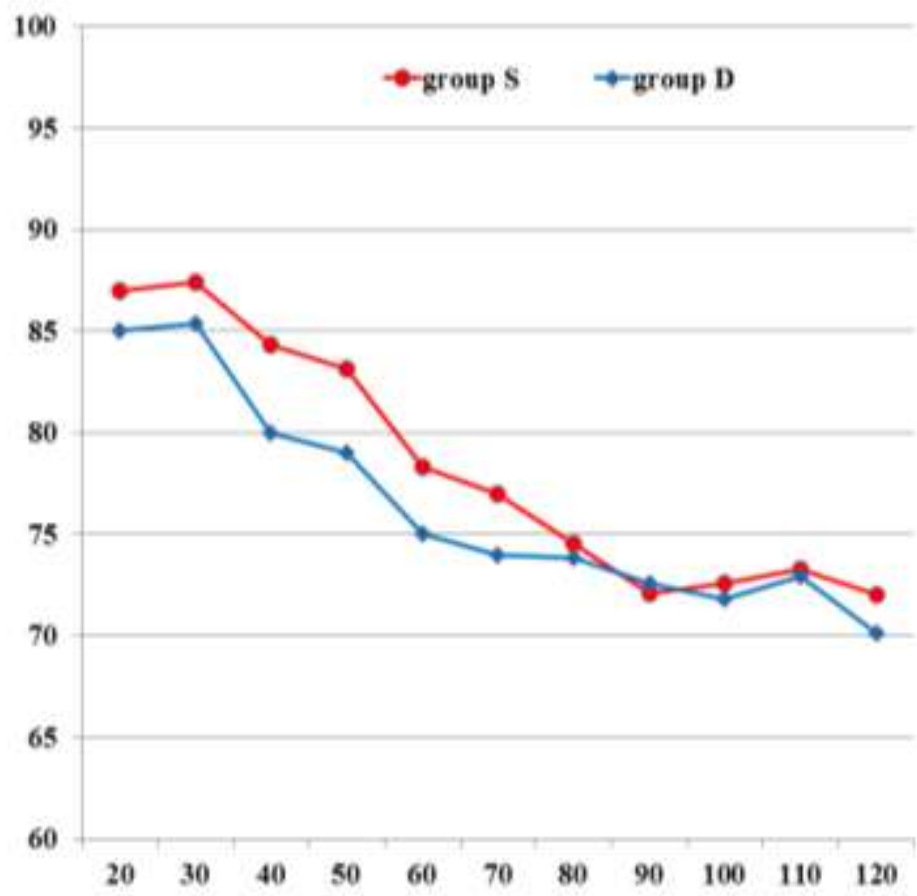

Figure (1): Comparing between the two groups as regards mean blood pressure
As regards mean blood pressure (MAP level), there was no statistically significant difference between the two study groups (Figure 1).

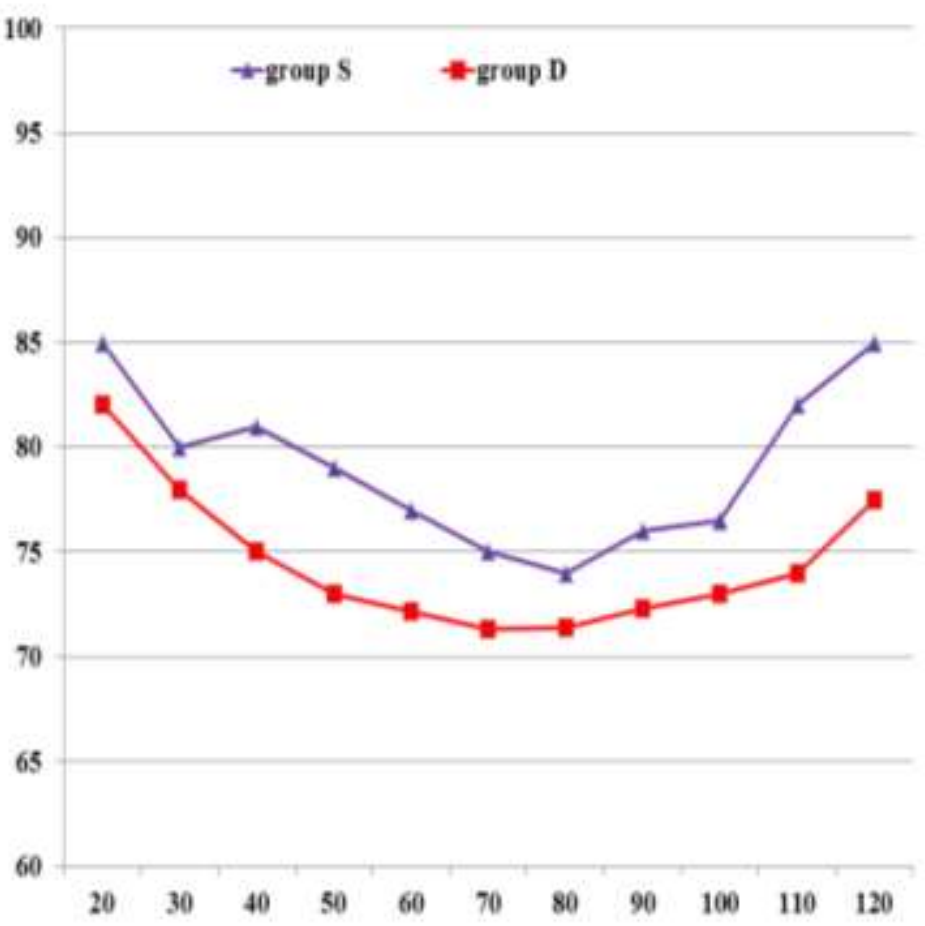

Figure (2): Comparing between two groups as regards heart rate

As regards heart rate (HR), there was a statistically significant difference between the two groups as heart rate was more significantly lower in group (D) compared to group (S) starting at 60 and continue to 120 min (Fig. 2). Two patients in group (D) experienced bradycardia (the lowest heart rate was 49 beat per minute and 51 beat per minute in these two patients) and were treated with atropine. In the other hand there was no bradycardia in group (S).

Table (3): Postoperative visual analog score for both groups

\begin{tabular}{|l|c|c|c|}
\hline Postoperative & $\begin{array}{c}\text { Group D } \\
(\mathbf{n = 2 5})\end{array}$ & $\begin{array}{c}\text { Group } \\
\mathbf{S}(\mathbf{n}=\mathbf{2 5})\end{array}$ & P value \\
\hline 30 minutes & $2.3 \pm 0.43$ & $6.2 \pm 3.21$ & 0.01 \\
\hline First hour & $2.7 \pm 1.54$ & $6.3 \pm 0.63$ & 0.01 \\
\hline Second hour & $2.4 \pm 0.21$ & $5.4 \pm 4.14$ & 0.02 \\
\hline 6 hour & $2.1 \pm 1.32$ & $3.6 \pm 0.43$ & 0.01 \\
\hline 10 hour & $2.1 \pm 0.31$ & $2.9 \pm 1.54$ & 0.01 \\
\hline 12 hour & $1.5 \pm 0.21$ & $1.9 \pm 0.21$ & 0.04 \\
\hline 24 hour & $1.3 \pm 0.13$ & $1.8 \pm 0.54$ & 0.03 \\
\hline
\end{tabular}

Table (3) showed that there was a statistically significant difference between the two groups as regards postoperative visual analog scale as it was higher in group (S) than group (D). 
Table (4): Comparing between two groups in regard to intraoperative fentanyl (mcg), first diclofenac $\mathrm{Na}$ dose request time and its postoperative total dose

\begin{tabular}{|l|c|c|c|}
\hline & $\begin{array}{l}\text { Group D } \\
(\mathbf{n = 2 5})\end{array}$ & $\begin{array}{c}\text { Group S } \\
(\mathbf{n = 2 5})\end{array}$ & $\begin{array}{c}\text { P- } \\
\text { value }\end{array}$ \\
\hline $\begin{array}{l}\text { Intraoperative } \\
\text { fentanyl (mcg) }\end{array}$ & $103 \pm 12$ & $156 \pm 33$ & 0.0001 \\
\hline $\begin{array}{l}\text { Time to first } \\
\text { Diclofenac Na } \\
\text { dose request in } \\
\text { min }\end{array}$ & $880 \pm 121$ & $325 \pm 77$ & 0.0001 \\
\hline $\begin{array}{l}\text { Postoperative } \\
\text { Diclofenac Na } \\
\text { dose (mg) }\end{array}$ & $76 \pm 37$ & $188 \pm 23$ & 0.0001 \\
\hline
\end{tabular}

Table (4) showed that there was a statistically significant difference between the two groups as regards the first diclofenac $\mathrm{Na}$ request time and postoperative total amount as (p-value 0.0001), we needed more time in group (D )for the first analgesic request $(880 \pm 121$ in $\mathrm{min})$ in comparison with (S) group ( $325 \pm 77$ in $\mathrm{min}$ ).

Table (5): Postoperative complications

\begin{tabular}{|l|c|c|c|}
\hline & $\begin{array}{c}\text { Group D } \\
(\mathbf{n = 2 5})\end{array}$ & $\begin{array}{c}\text { Group S } \\
(\mathbf{n = 2 5})\end{array}$ & P-value \\
\hline Nausea & 4 & 3 & 0.76 \\
\hline vomiting & 5 & 3 & 0.85 \\
\hline $\begin{array}{l}\text { Antiemetic } \\
\text { use }\end{array}$ & 5 & 3 & 0.85 \\
\hline $\begin{array}{l}\text { Hoarseness } \\
\text { of voice }\end{array}$ & 2 & 3 & 0.32 \\
\hline $\begin{array}{l}\text { Transient } \\
\text { discomfort }\end{array}$ & 5 & 4 & 0.23 \\
\hline
\end{tabular}

In terms of postoperative complications, there was no statistically significant difference between the two study groups (Table 5).

\section{DISCUSSION}

When used as an adjuvant in regional blocks, steroids prolong analgesia, but the results vary depending on the dose of dexamethasone, the concentration of the local anaesthetic, and the location of the block. The duration of analgesia prolongation with dexamethasone is highly variable, with some studies reporting analgesia lasting up to 20-24 hours and others reporting only 12-16 hours, as observed in this study $(\mathbf{6}, 7,8)$. Dexamethasone at doses greater than $0.1 \mathrm{mg} / \mathrm{kg}$ showed to be an effective adjunct in multimodal interventions to alleviate post-operative pain and opioid intake following surgery ${ }^{(9)}$. Since doses as low as $0.1 \mathrm{mg} / \mathrm{kg}$ failed to show any opioid-sparing effect when delivered intravenously. In the results of Desmet et $\boldsymbol{a l} .{ }^{\left({ }^{(9)}\right.} 8 \mathrm{mg}$ dexamethasone was used as an adjuvant with ropivacaine, claiming that IV and perineural dexamethasone are comparable in increasing the analgesic duration of regional anaesthesia.

Dexmedetomidine has been shown to have both sedative and analgesic effects as a highly selective $\alpha 2$ adrenoreceptor agonist $(\mathbf{1 0}, \mathbf{1 1}, \mathbf{1 2 )}$. Its intravenous role as a sedative, analgesic, and anxiolytic is well known, but may cause mild respiratory depression ${ }^{(\mathbf{1 3}, \mathbf{1 4})}$. The mechanism of dexmedetomidine in peripheral nerve blocks isn't entirely known, despite many studies on animals and humans. Membrane hyperpolarization occurs in peripheral myelinated and nonmyelinated fibers, resulting in sensory effects and pain during or after stimulation. It is believed to be triggered by the activation of the sodium-potassium pump following a temporary influx of sodium ions (15). Gaumann et al. ${ }^{(16)}$ discovered that the analgesic effect of peripheral perineural dexmedetomidine is caused by an increase in the hyperpolarizationactivated cation current in rats, which prevents the nerve from returning to a resting membrane potential for subsequent firing.

Our study noted that adding $1 \mathrm{ug} / \mathrm{kg}$ dexmedetomidine to levobupivacaine for plexus cervicalis block can reduce sensory block onset time, prolong analgesia length, and have a lower VAS score than the dexamethasone group. These results are consistent with Gaumann et al. ${ }^{(16)}$ and Brummett et al. ${ }^{(17)}$. Dexmedetomidine group had better hemodynamic stability than the control group. Dexmedetomidine is usually administered intravenously and provides analgesia and sedation, but the use of perineural dexmedetomidine combined with a local anaesthetic is becoming more common. There have been many findings on the use of perineural dexmedetomidine $(\mathbf{1 6}, \mathbf{1 7 )}$. Dexmedetomidine increased the length of bupivacaine anaesthesia and analgesia of nervus ischiadicus block in rats without causing nerve damage, according to Brummett et al. ${ }^{(18)}$. Also Gaumann et al. ${ }^{(16)}$ found the same findings in another rat sample.

In our study we found that The onset time of sensory block in group (D) was faster than in group (S). The difference was statistically significant ( $\mathrm{p}$ value was 0.007). Group (D) had a longer sensory block length time than group (S), and the difference was statistically significant (p-value was 0.004).

Also, there was a statistically significant difference in postoperative visual analogue scale scores between the two groups. It has been stated that adding a 2 adrenoreceptor agonist to local anesthetics is both safe and beneficial. Our results of cervical plexus block are similar to many other authors as Esmaoglu et al. ${ }^{(3)}$, Kaygusuz et al. ${ }^{(4)}$ 
and Rancourt et al. (19) that adding dexmedetomidine to a local anaesthetic for plexus brachialis block and posterior tibial nerve sensory blockade was safe in humans.

In our study, there was no statistically significant difference in mean vital sign (MAP level) between the two study groups. Still, there was a statistically significant difference in pulse (HR) between the two groups, with pulse significantly lower in the group (D) compared to group (S) from 60 minutes to 120 minutes, as dexmedetomidine has a double effect, acting as central sympatholytic. It does, however, have a dosage-related inhibition for blood pressure and heart rate. Esmaoglu et al. ${ }^{(3)}$ found several side effects in their research study, including hypotension and bradycardia (100 ug dexmedetomidine added to levobupivacaine for plexus brachialis block), as well as sedation and anxiolysis. In comparison to our findings, Abdallah et al. (20) found that intravenous or perineural dexamethasone improves the length of analgesia in the same way as a supraclavicular block with a long-acting local anaesthetic. Dawson et al. (21) also concluded that dexamethasone's effects are unaffected by the administration route. In contrast to our results, Rosenfeld et al. ${ }^{(22)}$ published a report recommend using dexamethasone intravenously to avoid the risk of neural toxicity. In contrast to our results, Herbland et al. ${ }^{(23)}$ denied that complete thyroidectomy with BSCPB using 0.75 percent ropivacaine enhanced postoperative analgesia. Also Eti et al. ${ }^{(24)}$ also concluded that BSCPB or wound infiltration did not affect postoperative analgesic requirements after thyroidectomy. There was no difference in pain ratings or total patient-controlled analgesia doses between groups. As shown by many studies and meta-analyses, the causes of such conflict may be unclear.

In contrast to our findings, another study found no statistically significant differences in pain ratings, analgesic intake, or nausea and vomiting after surgery between the treatment groups (ropivacaine with BSCPB and dexamethasone plus BSCPB). This means that the results of dexamethasone are almost identical regardless of the route of administration.

In our study, there was no statistically significant difference between the two groups in terms of postoperative complications such as vomiting, but Shih et al. ${ }^{(25)}$ found that using a BSCPB in addition to general anaesthesia reduced the incidence of nausea and vomiting during the postoperative period in parathyroid and thyroid operations. In parathyroid and thyroid operations. Shih et al. ${ }^{(25)}$ found that using a BSCPB in addition to general anaesthesia reduced the occurrence of nausea and vomiting in the postoperative period.

\section{CONCLUSION}

The addition of dexmedetomidine $1 \mu \mathrm{g} \mathrm{kg}-1$ to levobupivacaine for cervical plexus block decreased the time of onset of the sensory block and prolonged the period of analgesia and boosted the quality of analgesia so that patients are more sedated and less excitable than dexamethasone.

\section{REFERENCES}

1. Chetty S (2011): Dexmedetomidine for acute postoperative pain. South Afr J Anaesth Analgesia, 17: 139-140.

2. Panzer O, Moitra V, Sladen R (2011): Pharmacology of sedative-analgesic agents: dexmedetomidine, remifentanil, ketamine, volatile anesthetics, and the role of peripheral mu antagonists. Anesthesiol Clin., 29: 587605.

3. Esmaoglu A, Mizrak A, Akin A et al. (2005): Addition of dexmedetomidine to lidocaine for intravenous regional anesthesia. Eur J Anaesthesiol., 22: 447-451.

4. Kaygusuz K, Ozdemir K, Cevdet D et al. (2012): Effects of adding dexmedetomidine to levobupivacaine in axillary brachial plexus block. Curr Therapeutic Res., 73: 103-111.

5. Plunkett A, Shields C, Stojadinovic A et al. (2009): Awake thyroidectomy under local anesthesia and dexmedetomidine infusion. Mil Med., 174: 100-102.

6. Fouad H, Mohammed A, Ahmed S et al. (2016): Efficacy of preemptive dexamethasone added to bupivacaine in ultrasound guided transversus abdominus plain block for postoperative analgesia after inguinal herniorrhaphy. Am J Res Commun., 4: 27-42.

7. Kartalov A, Jankulovski N, Kuzmanovska B et al. (2015): Effect of adding dexamethasone as a ropivacaine adjuvant in ultrasound-guided transversus abdominis plane block for inguinal hernia repair. Pril Makedon Akad Nauk Umet Odd Med Nauki., 36: 35-41.

8. Knezevic N, Anantamongkol U, Candido K (2015): Perineural dexamethasone added to local anesthesia for brachial plexus block improves pain but delays block onset and motor blockade recovery. Pain Physician, 18: $1-4$.

9. Desmet M, Braems H, Reynvoet M et al. (2013): And perineural dexamethasone are equivalent in increasing the analgesic duration of a single-shot interscalene block with ropivacaine for shoulder surgery: A prospective, randomized, placebo-controlled study. Br J Anaesth., 111: 445-52.

10. Kauppila T, Kemppainen P, Tanila H (1991): Effect of systemic medetomidine, an alpha 2 adrenoceptor agonist, on experimental pain in humans. Anesthesiology, 74: 3-8.

11. Venn R, Bradshaw C, Spencer R et al. (1991): Preliminary UK experience of dexmedetomidine, a novel agent for postoperative sedation in the intensive care unit. Anaesthesia, 54: 1136-1142.

12. Baba Y, Kohase H, Oono Y et al. (2012): Effects of dexmedetomidine on conditioned pain modulation in humans. Eur J Pain, 16: 1137-1147. 
13. Aantaa R (1993): Dexmedetomidine, a novel alpha 2adrenergic agonist. A review of its pharmacodynamic characteristics. Drugs Future, 10: 49-56.

14. Frangoulidou E, Kuhlen R, Marenghi C (1998): Sedative agents and respiratory depression: a unique profile of dexmedetomidine. Series-Royal Society of Medicine, 221: 41-50.

15. Malmberg A, Hedley L, Jasper J et al. (2009): Contribution of $\alpha 2$ receptor subtypes to nerve injuryinduced pain and its regulation by dexmedetomidine. $\mathrm{Br}$ J Pharmacol., 132: 1827-1836.

16. Gaumann D, Brunet P, Jirounek P (1994): Hyperpolarizing afterpotentials in $\mathrm{C}$ fibers and local anesthetic effects of clonidine and lidocaine. Pharmacology, 48: 21-29.

17. Brummett C, Hong E, Janda A et al. (2011): Perineural dexmedetomidine added to ropivacaine for sciatic nerve block in rats prolongs the duration of analgesia by blocking the hyperpolarization-activated cation current. Anesthesiology, 115: 836-843.

18. Brummett C, Norat M, Palmisano J et al. (2008): Perineural administration of dexmedetomidine in combination with bupivacaine enhances sensory and motor blockade in sciatic nerve block without inducing neurotoxicity in rat. Anesthesiology, 109: 502-511.

19. Rancourt M, Albert N, Côté M et al. (2012): Posterior tibial nerve sensory blockade duration prolonged by adding dexmedetomidine to ropivacaine. Anesth Analg., 115: 958-962.
20. Abdallah $\mathrm{F}$, Johnson J, Chan $\mathrm{V}$ et al. (2015): Intravenous dexamethasone and perineural dexamethasone similarly prolong the duration of analgesia after supraclavicular brachial plexus block: a randomized, triple-arm, double-blind, placebo-controlled trial. Reg Anesth Pain Med., 40: 125-132.

21. Dawson R, McLeod D, Koerber J et al. (2016): A randomized controlled trial of perineural vs intravenous dexamethasone for foot surgery. Anesthesia, 71: 285290.

22. Rosenfeld D, Ivancic $M$, Hattrup $S$ et al. (2016): Perineural versus intravenous dexamethasone as adjuncts to local anesthetic brachial plexus block for shoulder surgery. Anesthesia, 71: 380-388.

23. Herbland A, Cantini O, Reynier P et al. (2006): The bilateral superficial cervical plexus block with $0.75 \%$ ropivacaine administered before or after surgery does not prevent postoperative pain after total thyroidectomy. Reg Anesth Pain Med., 31: 34-39.

24. Eti Z, Irmak P, Gulluoglu B et al. (2006): Does bilateral superficial cervical plexus block decrease analgesic requirement after thyroid surgery? Anesth Analg., 102: 1174-1176.

25. Shih M, Duh Q, Hsieh C et al. (2010): Bilateral superficial cervical plexus block combined with general anesthesia administered in thyroid operations. World J Surg., 34: 2338-2343. 